\title{
Negative Effects of Monolingual Culturalism in Translation
}

\author{
TU Chaolian, ZHONG Yahua \\ Wuhan Institute of Technology, Wuhan, China
}

\begin{abstract}
This thesis analyzes the translation of idioms, allusions, borrowing words and cultural images in the context of monolingual culturalism. The analysis shows that monolingual culturalism in translation can result in readers' misunderstanding and cultural intervention. The author further systematically lists four cross-cultural factors in translation and gives some translation approaches. Finally, the author suggests that both domestication and foreignization strategies should be applied in the process of translation to achieve cross-cultural communication.
\end{abstract}

Keywords: monolingual culturalism, readers' misunderstanding, cultural intervention, cross-cultural factors

\section{Introduction}

Translation plays an indispensable part in cross-cultural communication. Due to the diversity and inclusiveness of culture, translators must solve issues like cross-cultural communication in the first place and choose different translation strategies for different cultural factors (Sun, 2012; Zhang \& Sun, 2013). In 1995, American translation theorist Lawrence Venuti put forward the strategies of domestication and foreignization in The Translator's Invisibility-A History of Translation. The new concept has been studied for more than 20 years. For example, domestication and foreignization are not translation strategies but translation orientation and translators should adopt domestication orientation in language and foreignization orientation in culture (Yuan, 2010). Foreignization strategy should be applied in subcultures in literary works (Zhang, 2013). However, domestication cannot be ignored when we use foreignization, and translators must seek balance between the two (Chen, 1999). Translation is neither the transformation of symbols nor the explanatory replication of language, especially when we deal with cultural factors, monolingual orientation must be avoided. What's more, we should study the characteristics of the source language, consider the acceptance of readers, and then comprehensively apply domestication and foreignization strategies.

Monolingual culturalism means that translators pay too much attention to alien culture that is quite different from the translated language or target language (Li, Xia, \& Xie, 2009). Foreignization does not absolutely follow the norms of the language and discourse of the target language, and intentionally retains the empirical materials (Venuti, 1995). So there are similarities between monolingual culturalism and Venuti's foreignization, but Venuti's foreignization emphasizes on language processing and monolingual culturalism highlights cultural transmission. In the practice of translation, excessive attachment to culture of the source text will not only hinder cross-cultural communication but also cause cultural intervention.

Fund of the project: This research is funded by the key discipline construction project of the provincial universities in Hubei Province (Teaching and Research in Hubei [2012] No. 3).

TU Chaolian, MA, professor, MTI Center, School of Foreign Languages, Wuhan Institute of Technology, Wuhan, China.

ZHONG Yahua, postgraduate, MTI Center, School of Foreign Languages, Wuhan Institute of Technology, Wuhan, China. 


\section{Misunderstanding for Readers}

Religious idioms and historical allusions are the most common cultural elements of a country. Influenced by Christianity, westerners have already got used to the expressions from Bible in their daily lives. But in Sino-Tibetan culture, Buddhism has great influence on the lives of the Chinese people. Under the circumstance, if we use single translation strategy when dealing with texts with religious and historical factors, it is hard to achieve the transmission of different religious beliefs and cross-cultural comprehension.

Example1:

English: He does a lot of good jobs and is considered to be the salt of the world.

Chinese: 他做了很多好事, 是个了不起的人。

The phrase "the salt of the world" is Jesus' praise to one of his disciples. The connotative meaning is the most valuable members of society or a person or a group of people having the best character. Western Christians undoubtedly have no difficulty in understanding the expression, but if literal translation in foreignization strategy is applied here in order to propaganda the special meaning of salt in Bible, the target readers will feel confused, because salt is nothing but a kind of seasoning in Chinese culture. Instead, free translation will be much more acceptable for Chinese readers by translating it as "the most important man”. In translating the special phrase, cross-cultural comprehension is partially influenced by the translation strategy that the translator chooses, while translator's subjectivity may impact the images that culture embodies. When the translator senses that salt is a daily necessity based on his knowledge in his daily life, he will try to associate the text context with the common sense.

Apart from idioms from Bible, there are also big differences between Chinese historical allusions and western ones. And sometimes we cannot even find the corresponding cultural units such as material and social cultural-loaded words.

Example 2:

Chinese: 说曹操, 曹操到。

English: Speak of the devil, and he appears.

The original text comes from Romance of the Three Kingdoms, one of the four great classic novels in China, in which Emperor Liu Xie was to be pursued killing, and someone sent General Cao Cao (曹操) to save the emperor, but Cao did not appear until the last moment. Cao's final appearance surprised everyone and the emperor was eventually saved in the most dangerous situation. We can trace from the origin of the story that the phrase is indicative of the sudden and surprising appearance at a specific moment. Besides the very moment of the plot of the excerpt, we have to analyze the character or disposition of the people, saying Cao Cao is an ambitious antagonist and military counselor who wants to replace Liu and make himself the emperor. When English-speaking readers have little knowledge of the historical character, translators cannot adopt transliteration for the name. In fact, western superstition like "Speak of the devil and he doth appear" parallels similar expression to this Chinese phrase, which is used when an object of discussion unexpectedly becomes present during the conversation. The word "devil" is just what the character in the original text implies, so a corresponding expression in the target readers' culture can be borrowed in the process of translation. And the expression "Speak of the devil, and he appears" is much more appropriate than "Speak of Cao Cao, and he appears" for the general western readers. 
Therefore, in the process of translation, we should take the features of the source language and target language into account instead of following the principles of monolingual culturalism, otherwise the readers, as the subject of the cross-cultural communication, will be trapped in uncertainty and suspicion.

\section{Cultural Interventions}

Applied and preventive intervention research must consider cultural diversity as a matter of course (Dumas, Rollock, Prinz, Hops, \& Blechman, 1999). Cultural intervention includes the negative effects of culture on knowledge, beliefs, morality, law, and customs, as well as the ability and practice of an individual in society. Monolingual culturalism in translation mainly lies in the deviation of borrowing words through transliteration and cultural conflicts.

\section{Deviation of Borrowing Words}

Chinese character is pictograph, with its form closely connected with its meaning. Sometimes we can even guess the meaning according to the shape of the character. As a highly inclusive language, Chinese has assimilated many borrowing words in the process of translation. There are four categories of borrowing words in Chinese: sound substitution, new homophonic words, loan-translation words, and descriptive words, among which sound substitutions include words translated through foreignization strategy (Luo \& $\mathrm{Hu}, 2009$ ). Many early borrowing words in Chinese vocabulary derive from English-speaking countries with the dissemination of technology and industry, such as telephone, grammar, cement, ultimatum, and so on, most of which are translated into Chinese through transliteration. To some extent, transliteration gives impetus to the broad perception of Europeanization in China, and it cannot be denied that transliteration in translation can enrich both the Chinese and English vocabulary. As proven by the trend of globalization, both Chinese Xinhua Dictionary and Oxford English Dictionary (OED) have added some borrowing words that are useful for language users into their contents, but many new borrowing words from other culture can only be accepted or recognized by the locals through long years of experiment and practice. The early translated version of telephone, grammar, cement, and ultimatum, however, neither has any hieroglyphic meaning, nor complies with the structure and practice of the Chinese character, both of which can be regarded as the deviation of structuring Chinese words. Later, people began to retranslate these words according to the Chinese structure and the Chinese practices. In Oxford English Dictionary, many Chinese words such as "lose face”, "fengshui", and "hongbao" have already become part of English language, and then in 2018 the phrase "add oil" becomes another new word in OED, and the new phrase gives "oil” a quite distinctive meaning, which may not only take some time for the English-speaking people to get used to this new way of expressing support and encouragement to someone, but also cause deviation in the process of restructuring new English words.

As Chinese is character-formed and English is letter-formed, instead of applying transliteration, we should pay attention to parataxis and hypotaxis respectively in translating the borrowing words in both Chinese and English. Besides, target readers' acceptance as well as the ethics and values of the times cannot be neglected.

\section{Cultural Conflicts}

Cultural conflicts refer to the type of conflict that occurs when different cultural values and beliefs clash, which creates a situation where people are at odds with one another. Culture is heterogeneous and diverse, often resulting in subtle or big differences between the source language and the target language. If we completely replicate the source culture quite distinct from the targeted one in translation, cultural conflicts will 
appear as a result. Cultural images like animals, numbers, and social materials can be the cause of cultural conflicts if we attach more importance to either of the culture.

Example 3:

English: As wise as an owl.

Chinese: 像猴子一样聪明。

The cultural image of the original text is owl, a kind of wise, magical, and commendatory animal in western culture. As is shown in the film Harry Potter, the white cat is a magical bird helping to send messages between the dead and the alive and is usually endowed with hopeful and helpful meaning. However, in traditional Chinese culture, owl is sinister as it is fierce in appearance and shrill in sound, often howling and making its presence at dark night. One will naturally feel horrific when hearing its sound in the forest. Such being the case, cultural conflict is inevitable if the cultural image is applied mechanically in the translation, and the target readers will review the image of the metaphorical subject in their own culture. In Chinese culture, there are several clever animals, such as monkey, fox, and raven, but among them fox is somewhat cunning and raven is a kind of inauspicious animal in Chinese folk tales, and it is monkey that shares the similar positive meaning in both culture. So we can use it as a replacement of owl in conveying the cultural image so that cultural conflict can be avoided. In fact, there are numerous different animal images in Chinese and English culture, and in translating English animal images into Chinese ones, we should find a corresponding image in the target language, especially for words and phrases that have been used by Chinese for thousands of years, which is thought to be reasonable and acceptable for Chinese readers. Such kind of transition method can be regarded as borrowing translation. A few examples are mentioned here: the apple of one's eye (掌上明珠), wake a sleeping dog (打草惊蛇), neither fish nor fowl (非驴非马), a land of milk and honey (鱼米之乡). As cultural conflicts are caused by the essence of culture, we should take both the uniqueness of the original text and the translator's subjectivity into consideration, and use free translation and borrowing translation strategies to minimize the gap of cross-cultural communication.

\section{Four Cross-Cultural Factors in Translation and Approaches}

Systematically, there are four cross-cultural factors in translation, and they are exactly what impact the transmission of culture and cross-cultural communication. As in linguistics language has both connotative meaning and denotative meaning, the first cross-cultural factor culture identity has its extra meaning and pragmatic meaning. The corresponding words in two languages may have different extra meaning and pragmatic meaning, especially when it is contextualized. Moon, for example, often occurring in stanzas of many famous Chinese poems, either stands for nostalgia or love. And there are festivals related to moon in Chinese culture, while English-speaking countries do not have such tradition. So the meaning of moon is beyond what we usually regard as the planet or natural phenomenon, and its pragmatic meaning should not be mistaken in the process of translation. The second factor is aesthetic intervention, which refers to the preference or inclination for something in a certain culture. The distinction of preference contains the conception of nature, the perception of society, and the attitude toward beauty. As is shown in the ancient Chinese philosophy book Mencius, "harmony between human and nature" has become common folk's dominant view, so Chinese people tend to indulge themselves in nature. Westerners, however, believe that humans and nature are counterparts, and man can struggle to fight or challenge it and eventually conquer it. This can be seen in advertisement like Harley Davidson “American by Birth, Rebel by Choice”. In terms of the perception of society, the Chinese pay 
attention to collectivism and home is an everlasting theme in literature. But westerners pursue individualism and personal freedom. In terms of beauty, people's connoisseurship may vary from country to country and we cannot impose the standards or preferences in one culture on the other in translation. Cherry mouth or thick lips, high cheekbones or flat bridge of the nose, cream-colored or brown skin, or freckles on the face, each to one's own. Different connoisseurship in different culture often makes the translation task all the more difficult, and the fact is that people in one culture do not understand or even doubt the aesthetic judgment of the other. The third factor is political intervention. It means one's political ideology may have influence on the words he chooses in translating some sensitive words or phrases. For example, the phrase “形象工程” may have two English versions: prestige projects or vanity projects. And the latter can scarcely be heard in government reports or official broadcasts, for the word "vanity" is somewhat derogatory. The fourth is ethic intervention. It means the translator may abandon or change some of the components according to his moral beliefs, and the deleted or the changed part is what he believes should not be presented to readers. The early well-known Chinese translator Zhu Shenghao translated “the sister’s naughty” in Shakespeare’s play King Lear as “妹妹不 孝”, which means the sister’s unfilial. But in fact there are differences between "naughty” and "filial”. Zhu adopted such a way as filial piety is one of the most significant things for the Chinese people, and he directly chose a word that he thought was applicable.

In dealing with the above four cross-cultural factors, several principles should be followed, such as communicative purpose of the text, intertextuality of readers, compatibility of culture, and the position and function of that cultural factor in the whole system. Namely, we have to consider the structure of fluency of the translated text, cultural knowledge and experience of readers, the mainstream and compatibility for alien elements of the target culture, and the function of the cultural factor in the context so as to determine whether to retain, change, or remove it in translation. Culture resistance and cultural alignment are not literally and necessarily opposite, and we cannot only follow the principle of cultural resistance or the principle of cultural alignment to finish the task of translating the whole passage or even an excerpt. Transliteration, literal translation and amplification are domestication strategies, and free translation and omission belong to foreignization strategies. Only by combining the above principles and translation strategies can we provide the readers with satisfactory experience, or misunderstanding and cultural intervention will occur and thus cross-cultural communication will be a failure.

\section{Conclusion}

It is undoubted that monolingual culturalism can enrich the target language and promote cultural communication and transmission. But excessively focusing on the source language in translation will bring negative effects to the translated text and target culture. In the trend of globalization, we should follow the principles of dealing with cross-cultural factors and adopt both domestication and foreignization in the process of translation so as to avoid negative effects of monolingual culturalism.

\section{References}

Chen, L. L. (1999). Foreignization and domestication in translation. Chinese Science \& Technology Translators Journal, 12(2), 44-46.

Dumas, J. E., Rollock, D., Prinz, R. J., Hops, H., \& Blechman, E. A. (1999). Cultural sensitivity: Problems and solutions in applied and preventive intervention. Applied \& Preventive Psychology, 8(3), 175-196. 
Li, Y. L., Xia, Z. M., \& Xie, X. L. (2009). Research on the translation of Chinese and English culture. Beijing: China Yan Shi Press.

Luo, C. P., \& Hu, S. B. (2009). Language and culture. Beijing: Peking University Press.

Sun, Y. F. (2012). Translation and strategies for cross-cultural communication. Chinese Translators Journal, (1), 16-23.

Venuti, L. (1995). The translator's invisibility—A history of translation. London: Routledge.

Yuan, X. N. (2010). Issues of domestication and foreignization revisited. Journal of Southeast University (Philosophy and Social Science), 12(4), 84-88.

Zhang, Y. C., \& Sun, H. F. (2013). Reconstruction strategies of home culture in cross-cultural translation teaching. International Conference on Computer Science \& Education.

Zhang, Z. Q. (2013). An exploration of the conception of foreignizing translation. Hunan Normal University. 